\title{
Prevalence of Childhood Epilepsy in Canada
}

\author{
A.N. Prasad, X. Sang, B.A. Corbett, J.G. Burneo
}

\begin{abstract}
Rationale: Few data exist on the frequency and burden of childhood epilepsy in Canada and on the impact in the general population. We have assessed the point prevalence of childhood epilepsy in Canada. Methods: We analyzed data from the National Longitudinal Survey of Children and Youth ( $\mathrm{N}=20025$ for Cycle 2, and $\mathrm{N}=31960$ for cycle 3). Each cycle was collected over a two year period (2: 1996-1997, 3: 1998-1999). In the survey the following specific question was asked to the person most knowledgeable in the household: "Does the child have any of the following long-term conditions that have been diagnosed by a health professional?" The list of responses included Epilepsy and certain co-morbid conditions. In addition, a subsequent question identified whether the condition was treated by means of a specific anticonvulsant medication. (anticonvulsants or anti-epileptic pills?). Prevalence was based on the national standard population at the time of each survey. Results: In Cycle 2, 80 of 20025 subjects from 0 to 13 years old were described to have the diagnosis of epilepsy, yielding a weighted point prevalence of 4.03 per 1000 . In Cycle 3161 of 31960 children from 0 to 15 were described as having epilepsy, yielding a weighted point prevalence of 5.26 per 1000 . The rate of epilepsy was higher for males and increases with age. Conclusion: The overall rates for this age cohort are consistent with those obtained in other developed countries and seem to coincide with rates for youth and adults in Canada.
\end{abstract}

RÉSUMÉ: Prévalence de l'épilepsie chez l'enfant au Canada. Justification : Il existe peu de données sur la fréquence et le fardeau de l'épilepsie chez l'enfant au Canada et sur son impact dans la population en général. Nous avons évalué la prévalence ponctuelle de l'épilepsie chez l'enfant au Canada. Méthode : Nous avons analysé les données de $1^{\circ}$ Enquête longitudinale nationale sur les enfants et les jeunes (cycle $2: \mathrm{N}=20025 ;$ cycle 3 : $\mathrm{N}=31$ 960). Les données de chaque cycle ont été recueillies en deux ans (cycle $2: 1996-1997$; cycle $3: 1998-1999)$. Au cours de l'enquête, les questions spécifiques suivantes ont été posées à la personne la mieux renseignée du ménage : "L'enfant souffre-t-il de l'une ou l'autre des maladies chroniques suivantes, diagnostiquée par un professionnel de la santé?" L'épilepsie ainsi que certaines comorbidités faisaient partie de la liste des réponses possibles. De plus, une question subséquente demandait si la maladie était traitée au moyen d'un anticonvulsivant spécifique (pilules anticonvulsivantes ou antiépileptiques?). La prévalence était basée sur la population nationale au moment de chaque enquête. Résultats : Au cours du cycle 2, 80 des 20025 sujets de 0 à 13 ans ont été identifiés comme ayant reçu un diagnostic d'épilepsie, ce qui correspond à une prévalence ponctuelle pondérée de 4,03 par 1000 . Au cours du cycle 3, 161 des 31960 enfants de 0 à 15 ans ont été rapportés comme étant atteints d'épilepsie, ce qui correspond à une prévalence ponctuelle pondérée de 5,26 par 1000 . Le taux d'épilepsie était plus élevé chez les garçons que chez les filles et il augmentait avec l'âge. Conclusion : Les taux globaux pour cette cohorte d'âge sont en accord avec ceux obtenus dans d'autres pays industrialisés et semblent coïncider avec les taux rapportés chez les jeunes et les adultes au Canada.

Can. J. Neurol. Sci. 2011; 38: 719-722

There are few population-based studies on the prevalence of seizures disorders in children ${ }^{1-3}$ as prevalence studies are usually based on the case ascertainment of epilepsy from hospital visits, clinic databases, electroencephalogram (EEG) records, and emergency room records ${ }^{4}$. Furthermore, few Canadian data exist on the frequency of epilepsy, particularly in the childhood population $^{5,6}$. Data on prevalence rates of childhood epilepsy have varied from three to six cases per 1000 between studies of different age groups ${ }^{7,8}$.

Evaluating data from the Ontario Health Survey (OHS), and later from the National Population Health Survey (NPHS) and the Canadian Community Health Survey (CCHS), a point prevalence of self-reported epilepsy of 5.2 to 5.8 per 1000 population was obtained ${ }^{2,6}$. The OHS is an extensive survey in the Province of Ontario, while the NPHS and the CHS are national surveys, providing health-related and sociodemographic information in the Canadian population, but include mostly patients older than 12 years of age.
Using data from Cycles 2 and 3 of the National Longitudinal Survey of Children and Youth (NLSCY), we assessed the prevalence of childhood epilepsy in Canada.

\section{METHODS}

The National Longitudinal Survey of Children and Youth (NLSCY)

The NLSCY is a population based, long-term survey designed to measure characteristics and life experiences of

From the Department of Pediatrics (ANP), Faculty of Social Science (BAC), Department of Sociology, Department of Epidemiology and Biostatistics (XS, JGB), Epilepsy Programme (ANP, JGB), Department of Clinical Neurological Sciences, University of Western Ontario, London, Ontario, Canada.

Received January 5, 2011. Final Revisions Submitted March 23, 2011. Correspondence to: Jorge G Burneo, Epilepsy Programme, University of Western Ontario, 339 Windermere Rd, London, Ontario, N6A 5A5, Canada. 
children and youth in Canada as they grow from infancy to adulthood. The objectives of NLSCY are to determine the prevalence of various biological, social and economic characteristics and risk factors of children and youth in Canada; to monitor the impact of such risk factors, life events and protective factors on the development of these children; and to provide this information to policy and program officials for use in developing effective policies and strategies to help young people live healthy, active and rewarding lives.

The NLSCY was conducted bi-annually from 1994 to 2003. The target population for Cycle 1 consisted of 22831 Canadian children aged newborn to 11 years-of-age selected from three sources: (1) Statistics Canada's Labor Force Survey (LFS); (2) Statistics Canada's National Population Health Survey (NPHS). (3) Yukon and Northwest Territories. These children selected in Cycle 1 were followed from 1994 to 2003 as the longitudinal sample. In subsequent Cycles 1 through 4 , additional samples were added to fill the birth to two year old age cohort; therefore, these cycles can be analyzed as cross-sectional or used for longitudinal analyses.

Data were collected by face-to-face or telephone interview using computer-assisted interviewing (CAI). Questions were asked to the respondent in the home or by telephone and directly entered into a computer by the interviewer. The person that is most knowledgeable (PMK) about the child was asked to complete the questions.

\section{Case ascertainment and analysis}

Two cycles of the NLSCY data were analyzed. Cycle 2 was conducted from 1996 to 1997 with a sample size of 17832 and cycle 3 was conducted from 1998 to 1999 with a sample size of 27668 . The presence of epilepsy was probed by a specific question in the survey. Question HLT-Q45 in the survey asked the PMK "Does the child have any of the following long-term conditions that have lasted or are expected to last six months or more and have been diagnosed by a health professional". Epilepsy is one of the responses in the list along with allergies, bronchitis, heart condition or diseases, cerebral palsy, kidney condition or diseases and mental handicap. In addition, a subsequent question (HLT-Q51D) identified whether the condition was treated by means of a specific anticonvulsant or antiepileptic medication.

Cross-sectional samples were used from Cycles 2 and 3. Cycle 2 was collected in 1996-1997 and Cycle 3 was collected in 1998-1999. New respondents from 0 to 2 were added to the longitudinal sample in each cycle (2 and 3 ). Cross-sectional weights were calculated for each cycle to produce population estimates that were representative of the Canadian Census Population for each data collection period.

The numerator was the weighted cases, and the denominator was the weighted persons at risk. Data was analyzed using SPSS version 13.0. In addition, 95\% confidence intervals were calculated using the exact method.

Sampling weights were used with all calculations to account for the complex sampling design of the study. The sample weights represent the inverse probability of being sampled. For further information on weighting or other methodological issues relating to the NLSCY see the user guide, available at: http://www.statcan.gc.ca/dli-ild/data-donnees/ftp/nlscy elnej/nlcsy-elnej-cycle3-eng.htm.

\section{RESUlTS \\ Prevalence of Epilepsy (Table 1)}

In the NLSCY, the prevalence of epilepsy in Canadian children between 0-13 years (Cycle 2) was 4.03 per 1000 $(95 \% \mathrm{CI} ; 4.02,4.04)$ and in the age groups $0-15$ years (Cycle 3$)$, increased to 5.26 per 1000 children (95\% CI; 5.25, 5.27). A slight male preponderance was noted (M: F, 4.84:3.18 per 1000 children) in Cycle 2. This effect was more pronounced in Cycle 3 (M:F, 6.45:4.00 per 1000 children).

\section{Treatment of Epilepsy}

In a second analysis we used an item that asked whether the child was treated for six months or longer with anticonvulsants or antiepileptic drugs (HLTQ51D). A new variable for treated epilepsy was computed if the child had been diagnosed with epilepsy by a health professional (HLTQ45) and was treated for six months or longer with anticonvulsants or antiepileptic drugs. The prevalence of treated epilepsy dropped to 2.75 per 1000

Table 1: Prevalence of self reported Epilepsy in Canadian children using NLSCY data

\begin{tabular}{lll}
\hline & \multicolumn{1}{c}{$\begin{array}{c}\text { Prevalence per } 1,000(95 \% \mathrm{Cl}) \\
\text { Cycle 3 }\end{array}$} \\
\hline Child has epilepsy & $\begin{array}{c}\text { Cycle 2 } \\
\mathbf{0 - 1 3} \text { years old }\end{array}$ \\
\hline Preschool (0-5) & $4.03(4.02,4.04)$ & $5.26(5.25,5.27)$ \\
\hline School aged $(6+)$ & 0.90 & 1.43 \\
\hline Males with epilepsy & 6.31 & 7.47 \\
\hline Females with epilepsy & $4.84(4.82,4.86)$ & $6.45(6.43,6.47)$ \\
\hline Child taking AED & $3.18(3.16,3.20)$ & $4.00(3.98,4.02)$ \\
\hline Child has epilepsy \& on AED & $4.84(4.82,4.86)$ & $5.95(5.93,5.97)$ \\
\hline
\end{tabular}


(95\% CI; 2.74, 2.76) in Cycle 2 and 3.99 per 1000 (95\%CI; 3.98, 4.00 ) in Cycle 3. The prevalence figures for children who were treated with anticonvulsants were slightly higher than the prevalence figures for respondents who answered in the affirmative to the question HLTQ45 (4.84 vs 4.03 amongst Cycle 2 respondents and 5.95 vs. 5.26 amongst cycle 3 respondents) (Table 1).

Finally, in the cohort of newborn to 15 year olds nearly 16000 children and youth were diagnosed with epilepsy in Canada during the 1998-1999 data collection period. These estimates are based on a weighted population based sample from Cycle 3 of the NLSCY.

\section{Discussion}

The principal aim of this study was to calculate prevalence rates for epilepsy using data from the NLSCY survey. The NLSCY survey is longitudinal and truly population based. On account of its longitudinal nature one could examine age and time dependent changes in prevalence rates. The calculated prevalence rates from our analysis are remarkably similar to prevalence data estimated in other comparable childhood populations in the developed world. From this analysis, first, one is struck by the similarity and stability of prevalence rates from other Canadian studies with different population and age cohorts. Second, despite the different methods of case ascertainment (i.e., hospital based, administrative vs. population survey) employed in other studies, prevalence estimates across age groups are remarkably stable.

The prevalence rate in children increases in the school age cohort. This is not unexpected as more new cases are added in, while children diagnosed in previous years may not have achieved a remission. Thus the changes in prevalence between cycles can be explained in part by an increase in the age range studied, the population sample and biological plausibility.
Furthermore, a male preponderance in prevalence rates is noted in both cycles. Treatment prevalence by AED use is similar to the estimates of another study on Canadian children in Manitoba using data from the Population Health Research Data Repository (Table 2) ${ }^{9}$.

The prevalence of treated epilepsy (i.e. patient diagnosed and on AED) and the prevalence rates of diagnosed epilepsy are not concordant. The difference in rates (diagnosed epilepsy-treated epilepsy) though small (1.28 per 1000 in Cycle 2 and 1.27 per 1000 in Cycle 3) could be accounted for by several factors. Some of the common benign childhood epilepsies may not be treated with regular AED's (benign rolandic epilepsy) or treatment may be deferred until several epileptic seizures occur. In such situations it is not uncommon for children not to be on antiepileptic medication, while they carry a diagnosis of epilepsy. Many parents may carry the misperception that their children may have seizures, but may not be specifically told that their child has epilepsy. Another discordant note is struck by the observation that the proportion of children taking AED's is higher than those diagnosed with epilepsy. The off label use of AEDs in childhood neurological and psychiatric conditions has increased over the last two decades ${ }^{10}$. AEDs are presently used for treatment of chronic pain, headaches, Attention Deficit Hyperactivity Disorder, and psychoses. This expansion of off label use of antiepileptic drugs could likely account for the observed differences.

The study is important because it provides national data, as the previous available studies in children came from selected regions of Canada ${ }^{5.9}$, and because this type of study provides an idea of the burden of epilepsy on the childhood population and may help determine the need for health care, and contribute to future, more complex research ${ }^{6}$.

There are several limitations imposed by the nature of the condition being studied and the survey methodology used. The

Table 2: Prevalence of Epilepsy in children in other national and international studies

\begin{tabular}{llll}
\hline Reference & Age Range & Data Source/Region \& Country & $\begin{array}{l}\text { Prevalence per } 1,000 \\
\text { (Confidence intervals) }\end{array}$ \\
\hline $\begin{array}{l}\text { Larsson \& Eeg-Olofsson } \\
(2006)\end{array}$ & 1 m-16 years & $\begin{array}{l}\text { Hospital Register } \\
\text { Uppsala, Sweden }\end{array}$ & 3.4 \\
\hline $\begin{array}{l}\text { Eriksson \& Koivikko } \\
(1997)\end{array}$ & $0-15$ years & $\begin{array}{l}\text { Hospital Register } \\
\text { Finland }\end{array}$ & 3.9 \\
\hline Hauser \& Kurland & $0-11$ years & Rochester Epidemiology Project, & 2.6 \\
$(1991)$ & $12-14$ years & Minnesota & 6.2 \\
\hline Wiebe et.al & $0-11$ years & Ontario Health Survey, & 3.1 \\
$(1999)$ & $12-14$ years & Ontario, Canada & 5.7 \\
\hline Tellez Zenteno et al & $0-11$ years & National Population Health Survey, & $2.5(2.1-3.0)$ \\
$(2004)$ & $12-14$ years & Canada & $4.4(3.4-5.8)$ \\
\hline Tellez Zenteno et al & $0-11$ years & Community Health Survey & Not evaluated \\
$(2004)$ & $12-14$ years & Canada & $2.9(1.9-4.0)$ \\
\hline Kozyrskyj \& Prasad & $0-4$ years & Population Health Research Data & $3.46(2.96-4.05)$ \\
$(2004)$ & $5-9$ years & Repository & $3.63(3.13-4.17)$ \\
& $10-14$ years & Manitoba & $4.61(4.04-5.26)$ \\
& $15-19$ years & & $7.19(6.46-8.00)$ \\
\hline
\end{tabular}


condition of epilepsy is dynamic; as children grow older new cases can be diagnosed in some children and others may go into remission. There are no data on specific types of seizures or epilepsy syndromes collected in the survey. Definitions of active epilepsy and epilepsy in remission are not specified; therefore it is difficult to capture the total number of children who are impacted by epilepsy during childhood. Furthermore, the surveys did not include populations in rural, remote areas, and Indian Reserves. The exclusion of the latter population group is of importance as the epidemiology of epilepsy could be different due to different genetic and socio-demographic factors. However, the survey provides accurate information about Canadian children with epilepsy.

It may be argued that self-report measures used in survey methodology may be less reliable than measures diagnosed by a physician. Disorders that are rare or uncommon may give small sample sizes and result in a high sampling variance. To minimize such errors bootstrap weights have be used to calculate sampling variance. Results are reported with their confidence intervals and these are sufficiently narrow and comparable to results of other studies (Table 2 ) supporting the validity of our results. There are other sources of nonsampling errors that could potentially influence results namely; response errors due to sensitive questions, poor memory and recall, translated questionnaires, approximate answers, conditioning bias, non response errors and coverage errors. Statistics Canada makes several adjustments to minimize bias and reduce the effects of such nonsampling errors. Despite these limitations, we have demonstrated that the survey data is sufficiently robust to support analysis of a sub population of children with epilepsy. We hope to extend our analysis to examine comorbid conditions associated with childhood epilepsy, behavioral effects and cognitive outcomes in future studies. We will also provide Statistics Canada with feedback as to how some of the limitations of the current survey could be overcome to improve the quality of the data collected on child health issues pertaining to epilepsy.

Thus, we conclude that the NLSCY survey provides useful and valid estimates of prevalence of epilepsy and use of AED's in Canadian children from birth to 15 years. Future studies are planned to model socio-demographic and maternal factors in causation, as well as to analyse information on co-morbidities and cognitive and developmental outcome of children with epilepsy.

\section{CONFLICT OF INTEREST}

Jorge $\mathrm{G}$. Burneo has received financial support as he serves on the Advisory Board of UCB Canada and has received financial support for clinical research from UCB Canada, but not for this particular project.

\section{ACKNOWLEDGEMENTS}

Supported by Faculty Development Funds from the Department of Clinical Neurological Sciences, University of Western Ontario (JGB). Access to the NLSCY microdata files was granted through an application to the CISS-Access to the RDC's Program. While the research and analysis are based on data from Statistics Canada, the opinions expressed do not necessarily represent the views of Statistics Canada.

\section{REFERENCES}

1. Olafsson E, Hauser WA. Prevalence of epilepsy in rural Iceland: a population-based study. Epilepsia. 1999;40(11):1529-34.

2. Wiebe S, Bellhouse DR, Fallahay C, Eliasziw M. Burden of epilepsy: the Ontario Health Survey. Can J Neurol Sci. 1999;26 (4):263-70.

3. Wallace H, Shorvon S, Tallis R. Age-specific incidence and prevalence rates of treated epilepsy in an unselected population of 2,052,922 and age-specific fertility rates of women with epilepsy. Lancet. 1998;352(9145):1970-3.

4. Cowan LD, Leviton A, Bodensteiner JB, Doherty L. Problems in estimating the prevalence of epilepsy in children: the yield from different sources of information. Paediatr Perinat Epidemiol. 1989;3(4):386-401.

5. Camfield CS, Camfield PR, Gordon K, et al. Incidence of epilepsy in childhood and adolescence: a population-based study in Nova Scotia from 1977 to 1985. Epilepsia. 1996;37(1):19-23.

6. Tellez-Zenteno JF, Pondal-Sordo M, Matijevic S, Wiebe $\mathbf{S}$. National and regional prevalence of self-reported epilepsy in Canada. Epilepsia. 2004;45(12):1623-9.

7. Hauser WA. The prevalence and incidence of convulsive disorders in children. Epilepsia. 1994;35 Suppl 2:S1-6.

8. Hauser WA, Annegers JF, Kurland LT. Prevalence of epilepsy in Rochester, Minnesota: 1940-1980. Epilepsia. 1991;32(4): 429-45.

9. Kozyrskyj AL, Prasad AN. The burden of seizures in Manitoba children: a population-based study. Can J Neurol Sci. 2004;31(1):48-52.

10. Chen H, Deshpande AD, Jiang R, Martin BC. An epidemiological investigation of off-label anticonvulsant drug use in the Georgia Medicaid population. Pharmacoepidemiol Drug Saf. 2005;14(9): 629-38. 